\title{
Congenital aortic regurgitation in a child with a tricuspid non-stenotic aortic valve
}

\author{
RYOICHI HASHIMOTO, HARUO MIYAMURA, SHOJI EGUCHI \\ From the Department of Thoracic and Cardiovascular Surgery, Niigata University School of Medicine, Niigata City, \\ fapan
}

SUMMARY After follow up for seven years a 10 year old boy with congenital aortic regurgitation was found to have a tricuspid non-stenotic aortic valve at operation. The right coronary cusp was dysplastic, thickened, and contracted; the gap between its free margin and aortic wall was bridged with two fibrous bands; and the left coronary and non-coronary cusps were almost normal. The aortic valve was replaced with a prosthesis (St Jude Medical No 23), and the postoperative course was uneventful.

Congenital aortic regurgitation commonly coexists either with aortic valve stenosis or with ventricular septal defect. Congenital aortic regurgitation without any evidence of valve stenosis is rare. In addition, most patients have bicuspid aortic valves. We report a rare case of congenital aortic regurgitation in a patient with a tricuspid valve.

\section{Case report}

A 10 year old boy had had a heart murmur since the age of 3 years. He had no history of rheumatic fever or infective endocarditis. At the age of 3 years cardiac catheterisation showed severe aortic valve regurgitation. Because the diameter of the aortic annulus was small $(17 \mathrm{~mm})$ he was not operated on but was kept under observation as an outpatient. He was asymptomatic until the age of 10 when he was admitted to our department because his electrocardiogram showed ST segment and T wave changes in leads II, III, and aVF at rest and ST segment depression in leads V5 and V6 during exercise.

On admission he was $137 \mathrm{~cm}$ in height and $31 \mathrm{~kg}$ in weight with no sign of Marfan's syndrome. Blood pressure was $120 / 50 / 40 \mathrm{~mm} \mathrm{Hg}$ and pulse rate 96 beats/min and regular. A grade 4-6 (Levine) to and fro murmur was audible at the third intercostal space of the left sternal border, and a diastolic thrill was palp-

Requests for reprints to Dr R Hashimoto, Department of Thoracic and Cardiovascular Surgery, Niigata University School of Medicine, Asahi-machi 1, Niigata City 951, Japan. able. A short, low pitched mid-diastolic rumble was audible at the apex.

The chest $x$ ray film showed slight cardiac enlargement with a cardiothoracic ratio of 0.55 . The echocardiogram showed thickened aortic cusps and a dilated left ventricle (end diastolic dimension $5.6 \mathrm{~cm}$, end systolic dimension $3.4 \mathrm{~cm}$ ), but it was not clear whether the aortic valve was bicuspid or tricuspid. Cardiac catheterisation showed a slightly raised left ventricular end diastolic pressure $(11 \mathrm{~mm} \mathrm{Hg})$ and a mild pressure gradient across the right ventricular outflow tract $(15 \mathrm{~mm} \mathrm{Hg})$ but no pressure gradient across the aortic valve. The aortogram (Fig. la, b) showed severe aortic regurgitation and a dilated left ventricle. Left ventricular end diastolic volume and left ventricular end systolic volume were $230 \mathrm{ml}$ and $106 \mathrm{ml}$ respectively. Ejection fraction was 0.54 . Three aortic cusps were seen, although the right coronary cusp was small. The aortic annulus was $24 \mathrm{~mm}$ in diameter. The right ventriculogram (Fig. 1c) showed narrowing of the right ventricular outflow tract compressed by the dilated left ventricle.

At operation in January 1983 the aortic root was opened during cardiopulmonary bypass. The aortic valve had three commissures confirming that the aortic valve was not bicuspid. Both right and left coronary ostia were positioned normally. Inspection of the aortic valve showed the left coronary cusp and noncoronary cusp to be normal, apart from slight thickening near their commissures. The right coronary cusp was dysplastic, thickened, and contracted, and its free margin was bridged to the aortic wall with two fibrous bands (Fig. 2). The aortic valve was replaced with a St Jude Medical prosthesis No. 23. Histological exami- 

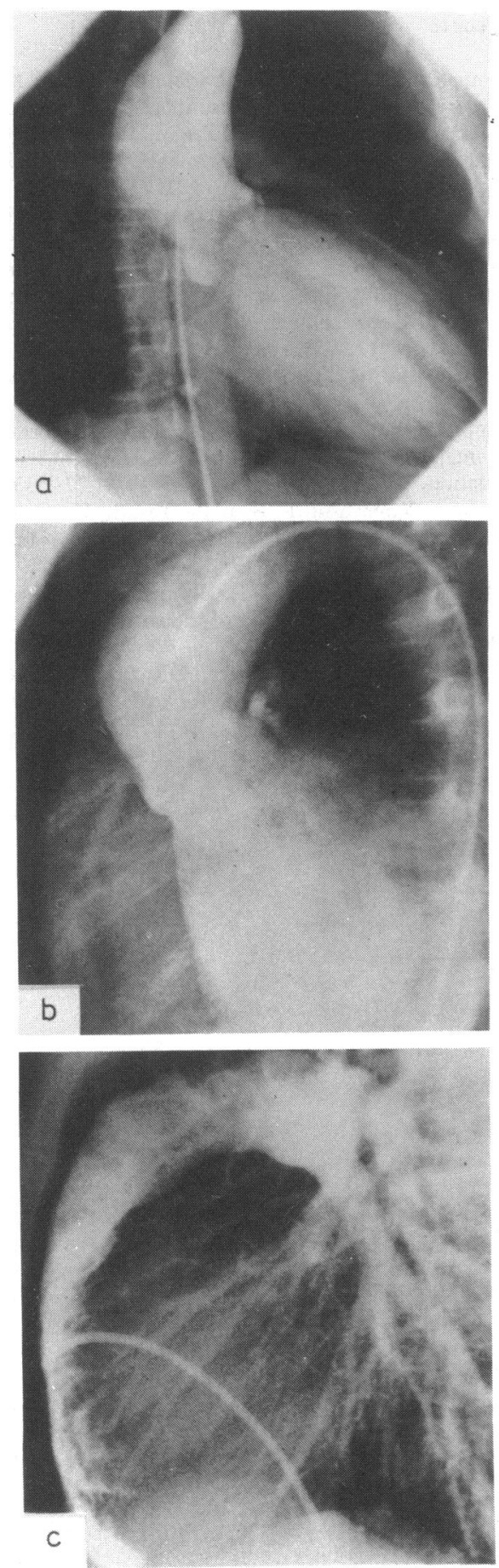

Fig. 1 (a) Anteroposterior and (b) lateral views of the retrograde aortogram show severe aortic regurgitation. Three aortic cusps are seen, although the right coronary cusp is small. (c) Lateral view of the right ventriculogram shows severely flattened right ventricle compressed by the enlarged left ventricle. nation of the excised aortic valve did not show any inflammatory or specific change, although there was some hyaline change.

The postoperative course was uncomplicated, and catheterisation and angiography were performed 27 days after operation. The dilatation of the left ventricle was much reduced (left ventricular end diastolic volume $128 \mathrm{ml}$, left ventricular end systolic volume 43 $\mathrm{ml}$ ), the compression of the right ventricle was relieved, and the pressure gradient across the right ventricular outflow tract had disappeared.

\section{Discussion}

Congenital aortic regurgitation is usually accompanied by another cardiac anomaly or by aortic valve stenosis. When it occurs in isolation infective endocarditis or rheumatic fever should be ruled out since these can cause aortic regurgitation in children. ${ }^{1}$

Frahm et al reported the first four cases of congenital isolated aortic regurgitation diagnosed during life. ${ }^{2}$ Whether the aortic valves were bicuspid or tricuspid was not definitely determined. Although Roberts et al and Fenoglio et al found three and four cases respectively of congenital isolated aortic regurgitation at necropsy, all had bicuspid aortic valves. ${ }^{34}$

Congenital isolated aortic regurgitation with three aortic cusps, as in our patient, is extremely rare, and to our knowledge few cases have been reported. Line et al reported a case with aortic valve regurgitation caused by the small left coronary cusp adhering to the aortic wall. ${ }^{5}$ In addition, this small rudimentary cusp completely occluded the left coronary ostium. Ando et

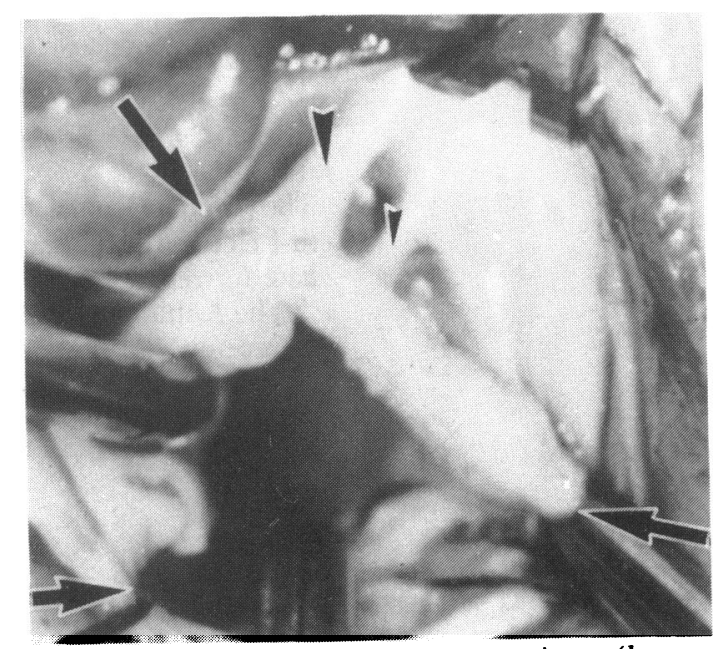

Fig. 2 Surgical findings showing three commissures (large arrows) and two fibrous bands (arrowheads) bridging the thickened free margin of the right coronary cusp to aortic wall. 
$a l$ reported congenital isolated aortic regurgitation in a boy deformed by thalidomide ${ }^{6}$; the aortogram showed three aortic cusps, but surgery was not undertaken. Kreel et al reported a case in which the right coronary cusp was closely adherent to the aortic wall, thus covering the orifice of the right coronary artery. ${ }^{7}$ This case, however, was complicated by supravalvular aortic stenosis.

The fibrous band connecting a free margin of the aortic cusp to the aortic wall, was described by Roberts $e t a l^{3}$ and closely resembled the fibrous bands in our case.

The optimal time for prosthetic valve replacement in a child is difficult to decide. Our patient was carefully followed for seven years and valve replacement performed when treadmill stress testing showed positive changes. In children, valve replacement should be postponed until the diameter of the aortic annulus becomes adequate. Operation is recommended for adult patients with isolated aortic valve regurgitation when left ventricular end systolic dimensions are 55 $\mathrm{mm}$ or more even in the absence of symptoms. ${ }^{8}$ No such criteria exist for children but electrocardiography on exercise can be performed at intervals and surgery should be considered when the stress test becomes positive.

\section{References}

1 Armistead SH, Lane I, McFarland R, Paneth M. The surgery of aortic valve disease in neonates, infants and children. $\mathcal{F}$ Cardiovasc Surg (Torino) 1982; 23: 140-4.

2 Frahm CJ, Braunwald E, Morrow AG. Congenital aortic regurgitation. Am $\mathcal{F}$ Med 1961; 31: 63-70.

3 Roberts WC, Morrow AG, McIntosh CL, Jones M, Epstein SE. Congenitally bicuspid aortic valve, causing severe, pure aortic regurgitation without superimposed infective endocarditis; analysis of 13 patients requiring aortic valve replacement. Am F Cardiol 1981; 47: 206-9.

4 Fenoglio JJ Jr, McAllister HA Jr, DeCastro CM, Davia JE, Cheitlin MD. Congenital bicuspid aortic valve after age 20. Am F Cardiol 1977; 39: 164-9.

5 Line DE, Babb JD, Pierce WS. Congenital aortic valve anomaly; aortic regurgitation with left coronary artery isolation. $\mathcal{F}$ Thorac Cardiovasc Surg 1979; 77: 533-5.

6 Ando J, Kobayashi T, Sato R, Yasuda H. Congenital aortic regurgitation observed in a thalidomide-deformed child. Fpn Heart $\mathcal{F}$ 1978; 19: 823-7.

7 Kreel I, Reiss R, Strauss L, Blumenthal S, Baronofsky ID. Supra-valvular stenosis of the aorta. Ann Surg 1959; 149: 519-24.

8 Henry WL, Bonow RO, Rosing DR, Epstein SE. Observations on the optimum time for operative intervention for aortic regurgitation; II. Serial echocardiographic evaluation of asymptomatic patients. Circulation 1980; 61: 484-92. 